\section{O Ensino da Sustentabilidade: uma Proposta Pedagógica de Sucesso em Prática na USP}

\author{
The Teaching of Sustainability: a Successful Pedagogical \\ Proposal in Practice at USP
}

\section{RESUMO}

Propostas de educação ambiental libertadoras e com conotação social têm sido o exemplo de trabalho apresentado pela Escola de Engenharia de São Carlos desde 1997, por meio do Curso de Especialização em Educação Ambiental do Centro de Recursos Hídricos e Ecologia Aplicada. Assim, o objetivo deste trabalho foi avaliar o processo pedagógico aplicado no referido curso à luz das mais efetivas tendências da educação ambiental, procurando atender um segmento carente da temática, que reivindica, urgentemente, propostas concretas. A ação do curso de especialização concentra-se em estimular a percepção da realidade local ou regional, educando para a conscientização individual e coletiva do papel desempenhado e da responsabilidade de cada ser humano junto ao planeta, ou seja, do "pensar global e agir local". O curso em foco completou 18 anos de atuação em nível nacional, capacitando profissionais das mais diversas formações, os quais consequentemente atuam como multiplicadores e mobilizadores na sociedade. Com conotação de extensão universitária, o curso atende aos objetivos de sustentabilidade das IES, em especial a Escola de Engenharia de São Carlos.

Palavras-chave: Universidade. Política de Sustentabilidade. Educação Ambiental. Extensão.

\section{ABSTRACT}

Liberating motions for environmental education with a social connotation have been the example of the work of São Carlos Engineering School since 1997, through the Specialization Course in Environmental Education at the Centre for Water Resources and Applied Ecology. The present paper evaluates the pedagogical process applied to the course in the light of the most effective trends in environmental education so that a needy segment of the theme can be met and concrete proposals can be urgently claimed. The Specialization Program focuses on stimulating the perception of local
Carlos Eduardo Matheus, America JaCintha de Moraes E JANETE BRIGANTE

Universidade de São Paulo. Escola de Engenharia de São Carlos, São Paulo, Brasil 
and/or regional reality and educating for individual and collective awareness of the role and responsibility of each human being regarding the planet, ie, the "thinking globally and acting locally". The course has been offered for 18 years at a national level and enabled professionals from diverse backgrounds to act as multipliers and mobilizers in the society. With a connotation of university extension, the course has met the sustainability goals of HEIs, in particular São Carlos Engineering School.

Keywords: University Sustainability Policy. Environmental Education. Extension

\section{INTRODUÇÃO}

\section{O conceito de desenvolvimento sustentável tornou-se aparente a partir da} década de 70, momento em que as sociedades começaram a perceber que os recursos naturais, até então considerados inesgotáveis, tinham um limite de uso que, se não respeitado, levaria os mesmos ao esgotamento. O crescimento econômico como um processo linear e infinito encontrava seus primeiros obstáculos, ou seja, a incapacidade dos ecossistemas em regenerar-se adequadamente frente à superexploração aliada à degradação ambiental. Várias conferências começaram a alertar sobre o perigo para a humanidade se não houvesse uma mudança no modelo de desenvolvimento (Estocolmo 72, Relatório Nosso Futuro Comum, Rio-92, Rio+10, Rio+20, entre outras). No bojo da Conferência Rio-92, mais de 170 países acordaram e ratificaram a Agenda 21 Global, um programa de ações que constitui a mais abrangente tentativa já realizada de promover, em escala planetária, um novo padrão de desenvolvimento. A Agenda 21 passou a ser reconhecida como um importante instrumento de planejamento para a construção de sociedades sustentáveis em diferentes realidades geopolíticas, conciliando métodos de proteção ambiental com aspectos de justiça social e eficiência econômica.

Após 18 anos da criação da Agenda 21, o estudo Global Biodiversity - Outlook 3 (Terceiro Panorama Global da Biodiversidade) realizado pelo PNUMA - Programa das Nações Unidas para o Meio Ambiente [15] revelou o nível drástico dos impactos antrópicos em escala global incidindo sobre o capital natural, um preocupante cenário que remete à uma reflexão da importância dada pelos governos ao cumprimento das metas daquela agenda. $\mathrm{O}$ referido estudo fez um alerta de que as taxas de extinções de espécies da fauna e flora nativa do mundo todo já atingiam valores 1000 vezes superiores às médias históricas e que as cinco principais causas destas extinções eram: a perda e degradação dos habitats, as mudanças climáticas, a poluição, o uso insustentável (super exploração) dos recursos e as espécies invasoras. A grande preocupação para a sociedade é que a destruição da biodiversidade ameaçará o fornecimento de alimentos, de medicamento e de água potável, como também ameaçará a polinização das culturas e a proteção contra as catástrofes naturais. Do exposto, depreende-se que a busca para o desenvolvimento sustentável, entendido como uma construção assentada em uma base ética (o compromisso intra e inter-gerações, considerando que o bem estar das gerações atuais não pode sobrepor-se e comprometer o das gerações futuras), demanda uma abordagem social, e não apenas cultural para solucionar os problemas, o que leva ao aprimoramento constante das propostas pedagógicas no campo da educação ambiental. 
Os grandes desafios da educação ambiental frente ao cenário de comprometimento das bases de sustentação da vida já haviam sido indicados pela Conferência de Tbilisi, em 1977, os quais continuam sendo bastante atuais, pois há a necessidade de se promover a integração e o envolvimento da comunidade, ou seja, uma ação de caráter participativo, considerando a opinião da comunidade; deve também ser transformador, estimulando mudanças de hábitos, atitudes e comportamentos; ser globalizante, considerando o ambiente global em seus múltiplos aspectos; ser permanente, promovendo e fortalecendo o senso crítico; ser contextualizador, privilegiando a realidade local sem perder a dimensão planetária e, finalmente, ser transversal, já que o meio ambiente se enquadra em todas as áreas do conhecimento [37].

Uma vez que a educação para a sustentabilidade trata de educar para o futuro, observa-se que os desafios da Conferência de Tbilisi e os da Agenda 21 têm sido progressivamente absorvidos e trabalhados pelas Instituições de Ensino Superior (IES) brasileiras como contribuição para a temática no país. A abordagem adotada pelas Instituições de Ensino Superior é propiciar meios para a capacitação e instrumentalização, tanto do seu público interno (docentes, técnicos e estudantes) quanto do público externo (comunidade em geral), para atuar na problemática ambiental. A Universidade, por meio de sua responsabilidade social e ambiental, deve ser uma facilitadora e fomentadora da tarefa de formação de cidadãos mais conscientes e mais críticos das questões socioambientais e aptos a participarem das soluções de vários problemas. As IES, ao criarem sua Política de Sustentabilidade, reconhecem, para tanto, a necessidade de integração de quatro importantes pilares: ensino, pesquisa/ inovação, gestão ambiental e extensão. Nesta arquitetura, as maiores demandas e desafios certamente estão nas atividades de extensão à comunidade.

No cenário da Universidade de São Paulo, focando na Escola de Engenharia de São Carlos, a tarefa de exercer o ensino e a extensão universitária tem um exemplo que ocorre desde 1997, o Curso de Especialização em Educação Ambiental idealizado e desenvolvido no Centro de Recursos Hídricos e Ecologia Aplicada (CRHEA-EESC-USP). Ao longo de seus anos de atuação, o referido curso evoluiu as estratégias para a prática da educação ambiental, buscando promover uma melhor interação e aproximação com a realidade das comunidades, além de um melhor entendimento da problemática socioambiental e das soluções necessárias e possíveis de serem executadas.

O Curso de Especialização em Educação Ambiental do CHREA, corroborando os desafios acordados na Conferência de Tbilisi e na Agenda 21 brasileira, está estruturado para apresentar e vivenciar vários aspectos da vivência humana no planeta. A riqueza de temas abordados no curso e a tradição do CRHEA nas pesquisas sobre os recursos hídricos em bacias hidrográficas geraram interessante oportunidade de potencializar estas características e dividi-las com a sociedade por meio de um modelo educativo. Este modelo, em constante evolução e aprimoramento, está voltado para a discussão e reflexão de todos os vieses que atuam na sociedade e que envolvem o uso dos recursos naturais, além de analisar a natureza dos impactos decorrentes do insuficiente planejamento e gerenciamento ambiental [3]. O objetivo do presente trabalho, portanto, é apresentar a evolução da experiência de extensão universitária no campo da educação ambiental promovida pelo Centro de Recursos Hídricos e 
Ecologia Aplicada, no âmbito da Escola de Engenharia de São Carlos.

Cenário Institucional e Histórico do Curso de Especialização em Educação Ambiental

O Curso de Especialização em Educação Ambiental do CRHEA, doravante abreviado neste artigo como CEEA, tem como base institucional a Escola de Engenharia de São Carlos da Universidade de São Paulo (EESC-USP). A EESC está localizada no município de São Carlos desde 1953 e tem foco nas engenharias Civil, Mecânica, Elétrica, Produção Mecânica, Arquitetura, Hidráulica e Saneamento, sendo que na atualidade abrange renomados institutos e centros de pesquisa nas áreas correlatas.

Destaca-se que, no ano de 1966, foi estruturado, na EESC, o Departamento de Hidráulica e Saneamento (SHS), oriundo da junção das cátedras de Física Técnica, Hidráulica e Saneamento. Desde o início de seus trabalhos o SHS, em nível institucional e/ ou departamental, caracterizou-se por uma atenção no binômio ensino-pesquisa. Em 1973 foi fundado, no âmbito deste Departamento, e com apoio da Fundação de Amparo à Pesquisa do Estado de São Paulo (FAPESP) e da Financiadora Nacional de Estudos e Projetos (FINEP), um centro de pesquisas multidisciplinares com atividades nas Ciências Ambientais, denominado Centro de Recursos Hídricos e Ecologia Aplicada (CRHEA), que está instalado no município de Itirapina e às margens da represa Carlos Botelho (represa do Broa). O CRHEA, ao longo dos anos, passa a sediar o curso de pós-graduação em Ciências da Engenharia Ambiental (PPG-SEA-SHS-EESC-USP).

A partir da criação do PPG-SEA (Programa de Pós Graduação em Ciências da Engenharia Ambiental), o volume de pesquisas movimentadas pelo programa deu subsídios para que em 1986 fossem propostos e desenvolvidos projetos na linha da Educação Ambiental. Em uma primeira versão, de 1986 a 1991, foram realizados cursos voltados para o "Sistema de Atualização de Ciências e Geografia com a Utilização da Bacia Hidrográfica como Unidade de Ensino”, coordenado pelo Prof. Dr. José Galízia Tundisi e pelo Prof. Dr. Dietrich Schiel, em parceria com o Centro de Divulgação Científica e Cultural (CDCC-EESC-USP). O público-alvo era o de professores da rede de ensino de $1^{\circ}$ e $2^{\circ}$ graus de São Carlos e região, especialmente o professor de Ciências, tendo como unidade de estudos a bacia hidrográfica do Ribeirão do Lobo, um dos contribuintes da represa do Broa. Naquele período, as atividades do curso duravam dez dias, coincidindo com o período de férias escolares. Nesta ocasião, e por muitos anos seguintes, foi criado, para subsidiar o curso, um "Instituto Aberto" (no próprio CRHEA) que permitia o retorno desses professores com os seus alunos para continuidade dos trabalhos de educação ambiental durante o ano letivo [16].

De 1991 a 1993, sob a mesma coordenação, o curso recebeu sua primeira reformatação, transformando-se em um curso de aperfeiçoamento: "Educação Ambiental: A Bacia Hidrográfica como Método de Abordagem e Ensino”. Este curso visava o treinamento de professores de Ciências da rede de ensino público em medidas da qualidade da água e interpretação dos dados, relacionando-os com os usos da bacia hidrográfica. Para atender este objetivo, foi elaborado, no CRHEA, um kit para análises de qualidade da água que, após o curso, era cedido para as equipes de professores das diversas regiões 
do Estado de São Paulo, de forma que pudessem explorar as bacias hidrográficas de suas cidades durante as práticas da educação ambiental com seus alunos.

A partir de 1993 houve uma ampliação do curso envolvendo professores de outros estados do Brasil. Neste período ocorreu a participação de diversos profissionais da própria USP no projeto de Educação Ambiental do ILEC (International Lake Environment Commitee Foundation), órgão sediado no Japão, congregando pesquisadores de diversas partes do mundo na gestão integrada de bacias e reservatórios, o que estimulou ainda mais os idealizadores do curso na construção da temática. Os princípios, objetivos, métodos de avaliação e perspectivas futuras destes projetos podem ser explorados e entendidos na consulta aos trabalhos de Tundisi [28, 29, 33, 34], Tundisi \& Schiel [36], Tundisi et al. [30] e Tundisi et al. [31, 32, 35].

A nova reformatação do curso ocorreu a partir de 1993, um reflexo da colaboração da Dra. Elisabete Gabriela Castellano, especialista da área de Educação, com trabalhos sobre a teoria piagetiana [4], o que permitiu criar uma ligação entre os primeiros formatos do curso para novos formatos ampliados, como o "Curso de Aperfeiçoamento em Educação Ambiental" com carga horária de 180 horas. Na sequência, a partir de 1997, estabeleceu-se a terceira reformatação do curso, contendo uma carga horária ampliada para 360 horas, com vários momentos sendo apoiado pela FAPESP.

Entre 1997 e 2000, o título do curso evolui de "Curso de Especialização em Educação Ambiental com foco na Bacia Hidrográfica como Método de Abordagem e Ensino", para "Curso de Especialização em Educação Ambiental e Recursos Hídricos: Perspectivas para o Século XXI” e, a partir de 2010, o título foi novamente alterado para "Educação Ambiental e Recursos Hídricos: Desenvolvendo Ações Socioambientais". Após 18 anos de aplicação, o curso tem buscado realizar o seu papel na formação de cidadãos mais conscientes das questões sociais e ambientais, ancorando-se na abordagem sistêmica de bacias hidrográficas, o que oferece um cenário apropriado para explorar uma visão holística e integrada do ambiente.

\section{Estrutura e Funcionamento do CEEA}

\section{Linha Pedagógica}

Para entender a estrutura do CEEA é necessário refletir sobre o exercício de educar para a sustentabilidade. Segundo Castro e Spazziani [5], a educação ambiental, através de sua preocupação com a qualidade ambiental e social em nível local, regional e global, deve atender aos fatores econômicos, sociais, políticos e ecológicos que propiciam os problemas ambientais, de modo a favorecer um basculamento nos paradigmas enraizados nas pessoas, tornando os indivíduos mais suscetíveis ao desenvolvimento de um novo olhar sobre as inter-relações indissociáveis entre as necessidades do homem e os limites da natureza.

Neste viés, a estrutura do curso busca seguir a linha pedagógica do educador Paulo Freire [7], uma vez que esta se posiciona adequadamente com os objetivos, características e princípios reconhecidos como necessárias para uma educação ambiental plena. $\mathrm{O}$ destaque dos trabalhos de Freire decorre da aliança entre a teoria e a prática. Importa 
para o autor o "aprender fazendo", o que representou uma inovação na realidade pedagógica de sua época. Seu método consiste em três momentos dialéticos e interdisciplinares que se entrelaçam: a investigação temática, a tematização e a problematização. Nesta sequência, todo o seu pensamento tem uma relação direta com a realidade (a ser transformada). $\mathrm{O}$ autor acredita que a aplicação dos três momentos leva os indivíduos para uma transformação; de passivos observadores a pessoas mais críticas, potencialmente transformadoras da realidade. A evolução desta forma de conduzir a educação contribuiu para o desenvolvimento do conceito de Pesquisa Participante, adotado pelo curso.

De acordo com Gajardo [8], a "Pesquisa Participante ou Participativa é o termo usado com freqüência para fazer referência às experiências que procuram conhecer transformando. É utilizado para designar esforços diversos no desenvolvimento de práticas de pesquisa que incorporem os grupos excluídos das esferas de decisão, à produção e comunicação de conhecimentos, como ações que disso possam derivar". Paulo Freire ainda cita que, neste tipo de pesquisa "é proposta uma interação mais efetiva entre pesquisadores e comunidade, aspirando-se uma comunicação a mais horizontal possível entre os participantes, ou seja, não há objetos de estudo e sim uma relação de sujeito versus sujeito". Além disso, utiliza-se o diálogo como o meio de comunicação mais importante no estudo e na coleta das informações, rompendo-se, sempre que possível, o monopólio do saber e do conhecimento.

A arquitetura pedagógica do CEEA, ancorada no conceito de Pesquisa Participante, guarda semelhanças com outro importante método conhecido como Metodologia da Problematização ou Arco de Maguerez, criado por Charles Maguerez [2]. Esta metodologia consta de cinco etapas que se desenvolvem a partir da realidade ou de um recorte da realidade, quais sejam: 1 . Observação da Realidade; 2. Pontos-Chave; 3. Teorização; 4. Hipóteses de Solução e 5. Aplicação à Realidade (prática). O Método do Arco de Maguerez foi elaborado na década de 70 e tornado público por Bordenave a partir de 1977, mas na época foi pouco utilizado na área da educação. No Brasil, este método está retomando o seu valor após ter sido incluído na Lei de Diretrizes e Bases da Educação no 9394, de 20 de dezembro de 1996, a qual norteia a utilização de metodologias ativas no processo ensino aprendizagem.

A linha pedagógica de Freire, como também a linha da Metodologia da Problematização, exige expor as múltiplas relações da realidade entre o homem e o ambiente. Corroborando estas exigências, o CEEA, por meio de uma diversidade de disciplinas e da transversalidade, expõe o cenário que envolve a gênese dos problemas ambientais, grande parte deles ocasionados pelas atividades antrópicas. A natureza dos conteúdos pedagógicos do curso inclui ecopedagogia, percepção e interpretação (atividades lúdicas), psicologia e meio ambiente, educação ambiental na rota transversal dos muitos ângulos das sociedades, espiritualidade e aspectos da ecologia como: estrutura e funcionamento dos ecossistemas (aborda também, direta e indiretamente, ciclos biogeoquímicos e de nutrientes, resiliência e capacidade suporte, fluxo de energia e biodiversidade), serviços ambientais, ecologia humana, economia ambiental, resíduos sólidos e seus impactos, legislação, recuperação ambiental, entre outros.

Nessa diversidade de temas, a preocupação em repassar conhecimentos sobre o funcionamento dos ecossistemas se apoia na premissa adotada pelos coordenadores 
do curso de que um cidadão moderno precisa compreender e usar de modo sustentável os complexos sistemas ambientais dos quais faz parte [37]. Acredita-se que a compreensão sobre como funcionam os sistemas ambientais e, especialmente, quais são os seus limites, muito colabora para redirecionar as formas de uso dos mesmos.

Com os temas definidos, a estrutura de 360 horas do curso é dividida em quatro módulos presenciais distribuídos num período de 1,5 anos. As disciplinas são ministradas por profissionais parceiros oriundos de várias universidades, centros de pesquisa e outras instituições, incluindo profissionais da própria USP. Entre um momento presencial e outro vai sendo tecida uma conexão ou interligação cada vez mais próxima entre os alunos do curso e os professores, especialmente por meio da linha de trabalho ou do projeto, que cada um é orientado a desenvolver. O projeto que cada aluno desenvolve é o estímulo para que transcendam a participação e exercitem a ação. Da mesma forma, estes projetos são a base para aplicação dos conhecimentos compartilhados entre professores, alunos e comunidade.

A Pesquisa Participante é, portanto, um dos elementos enriquecedores e transformadores da prática da educação ambiental. Neste contexto, é interessante destacar Thiollent [27], que acredita que para uma real mudança de valores ou transformação não basta somente a "participação", mas também uma forma de ação planejada (um projeto). $\mathrm{O}$ autor ainda frisa que quando ocorre uma ação, desencadeia-se a "pesquisa-ação", ou seja, "um tipo de pesquisa social com base empírica que é concebida e realizada em estreita associação com uma ação ou com a resolução de um problema coletivo e no qual os pesquisadores e os participantes representativos da situação, ou do problema, estão envolvidos de modo cooperativo ou participativo". Nesse sentido, cada projeto desenvolvido pelos alunos do CEEA em diferentes cidades e bacias hidrográficas, embora siga um padrão de Pesquisa Participante, possui também estímulos à Pesquisa Ação, com objetivos calcados na solução participativa de problemas identificados nas suas comunidades de origem.

\section{Referenciais Metodológicos}

Há diferentes ferramentas e/ou métodos científicos e pedagógicos colocados à disposição dos alunos que participam do CEEA. Muitas das ferramentas científicas utilizadas auxiliam nas várias práticas in loco (como também em laboratório), a exemplo das atividades de coleta de água em rios e represas para análise de variáveis físicas, químicas e biológicas. Neste caso específico, faz-se uso de um kit de análise de água desenvolvido no próprio CRHEA, o qual incorpora uma evolução de métodos e parâmetros indicadores preliminares de qualidade da água, sendo possível medir temperatura, oxigênio dissolvido, $\mathrm{pH}$, condutividade elétrica e transparência da água. Dados desta natureza oferecem muitos elementos de discussão e compreensão do funcionamento dos biossistemas.

As atividades in loco permitem que os alunos testem suas hipóteses, reformulem ou complementem as suas teorias. Tamaio [25], citado em Moraes [16], diz que a observação da natureza (trabalhos em campo) auxilia no desenvolvimento da capacidade cognitiva do ser humano, facilitando a compreensão das intrincadas questões ambientais. Segundo o autor, nestes momentos o campo se transforma no laboratório 
onde se concretizam, emergem e interagem os conteúdos teóricos elaborados em sala de aula, com a realidade concreta das informações da natureza. É o local onde se confrontam os valores exibidos de dentro de "quatro paredes" com os praticados nas atividades de campo. Por isso, é preciso fomentar experiências de aprendizagem que engajam os estudantes em projetos complexos do mundo real e que as escolas sejam comunidades de aprendizes onde experiências e desafios intelectuais possam ser realmente vivenciados e não apenas verbalizados.

No mesmo diapasão, para atender às necessidades de multiplicar os temas transversais inerentes da educação ambiental, faz-se uso de variadas metodologias pedagógicas construtivistas, ajustadas ao princípio adotado de que é preciso sempre respeitar o aluno e aproveitar as experiências de vida que ele traz, uma vez que todos (professores e alunos) são atores da história. A prática construtivista do curso é assim exercida com trabalhos em grupos, leituras de textos, livros, jornais, interpretação de mapas, momentos lúdicos (sensibilização musical, dança, teatro, composição artística, etc.), mini-cursos e oficinas e práticas que estimulem o espírito de cooperação. Em todas estas atividades é priorizado manter espaço para que o aluno construa seu próprio conhecimento, o que se consegue evitando fornecer definições prontas e conceitos

acabados [23]. Tanto as atividades de campo quanto as adotadas em sala buscam a sensibilização como estágio que propicia interferências nos valores e conceitos interiores do ser humano que, uma vez incentivados, conduzem à modificação dos níveis de percepção e interpretação ambiental [10]. Trabalhos em campo e de sensibilização geram um clima permeado de muitas reflexões.

\section{Caráter Interdisciplinar do Curso}

As sucessivas reformatações que ocorreram na estrutura do CEEA permitiram incorporar não somente os professores da rede de ensino, mas também outros profissionais interessados na área, estabelecendo um caráter interdisciplinar, de modo que em uma mesma discussão ocorram visões de diferentes formações profissionais, gerando uma análise fecunda da problemática ambiental.

Existe um consenso de que um profissional de educação ambiental reflexivo e crítico terá que incorporar em seus conhecimentos a prática interdisciplinar, pois a complexidade das relações homem/natureza no processo de desenvolvimento contemporâneo, representada por inovações tecnológicas, crescimento das cidades, descoberta da finitude da riqueza, degradação do ambiente com a ameaça de falência dos recursos naturais, em especial a água, está a exigir estudos e práticas interdisciplinares. Portanto, a interdisciplinaridade implica uma forma de se organizar e trabalhar o conhecimento, buscando uma interação nas diferentes dimensões dos fenômenos estudados e observação da realidade de modo não fragmentado [6].

Para representar esta interdisciplinaridade, ao longo dos 18 anos de aplicação do CEEA, participaram 47 diferentes formações profissionais, com destaque para biólogos, geógrafos, advogados, pedagogos, químicos e turismólogos (Gráfico 1). Uma análise da diversidade profissional por turma que concluiu o curso até o ano de 2010 revelou que, em média, turmas de 42 alunos reúnem, em um mesmo espaço de interação, 16 diferentes profissionais. 
Gráfico 1 - Formações profissionais e número de alunos que concluíram o CEEA até o ano de 2010.

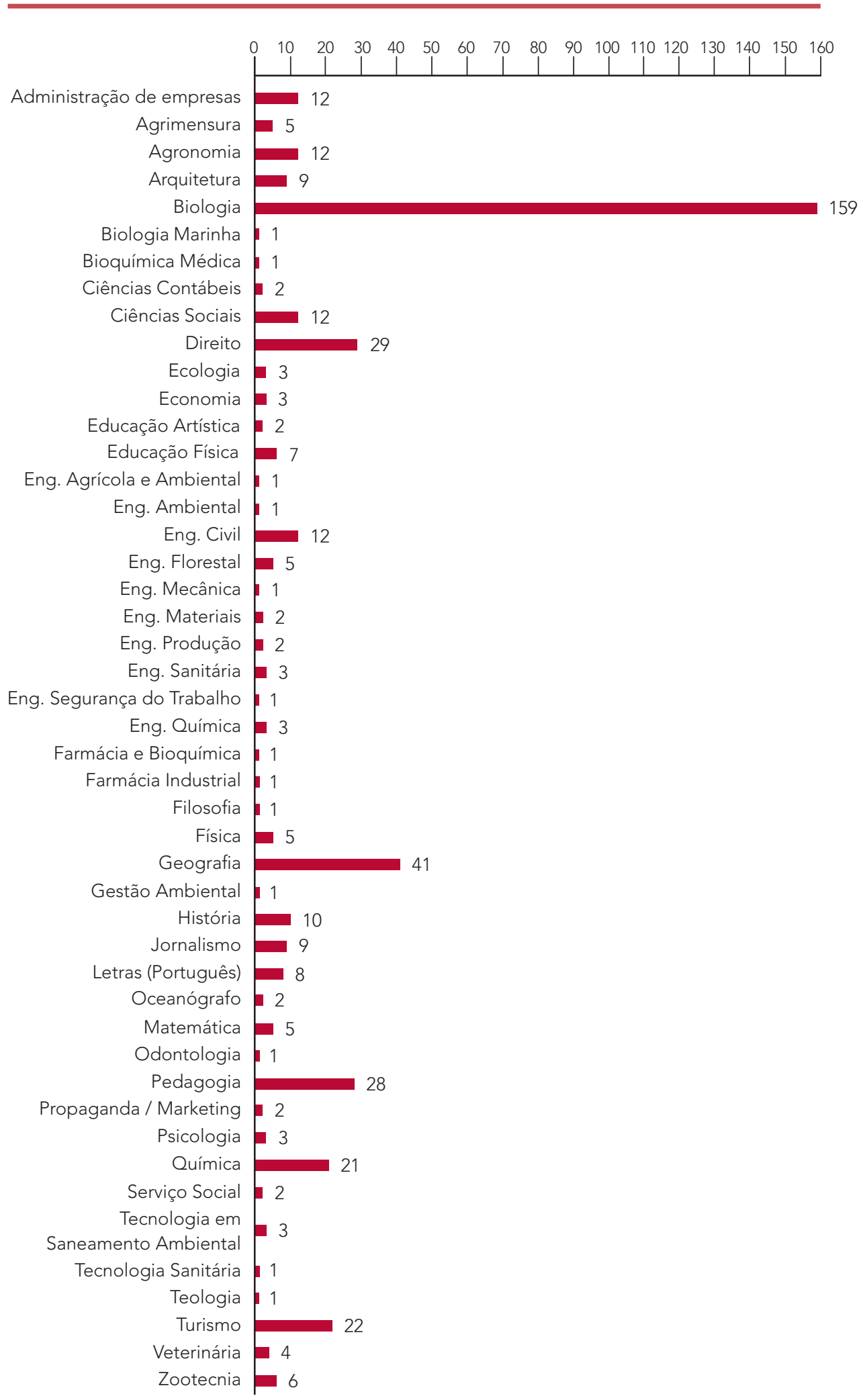


A diversidade de profissionais que ingressaram no curso somado a uma maior inserção territorial do mesmo, permite que as turmas congreguem diferentes realidades, demandas e experiências nacionais (Gráfico 2). Até o ano de 2010 foram 20 estados da Federação representados por um ou mais municípios com alunos ingressados no curso, destacando-se São Paulo (102 municípios), Minas Gerais (11 municípios) e Paraná ( 9 municípios).

Gráfico 2 - Relação dos estados da federação e o número de municípios que os representa, e que tiveram alunos concluindo o CEEA até $o$ ano de 2010.

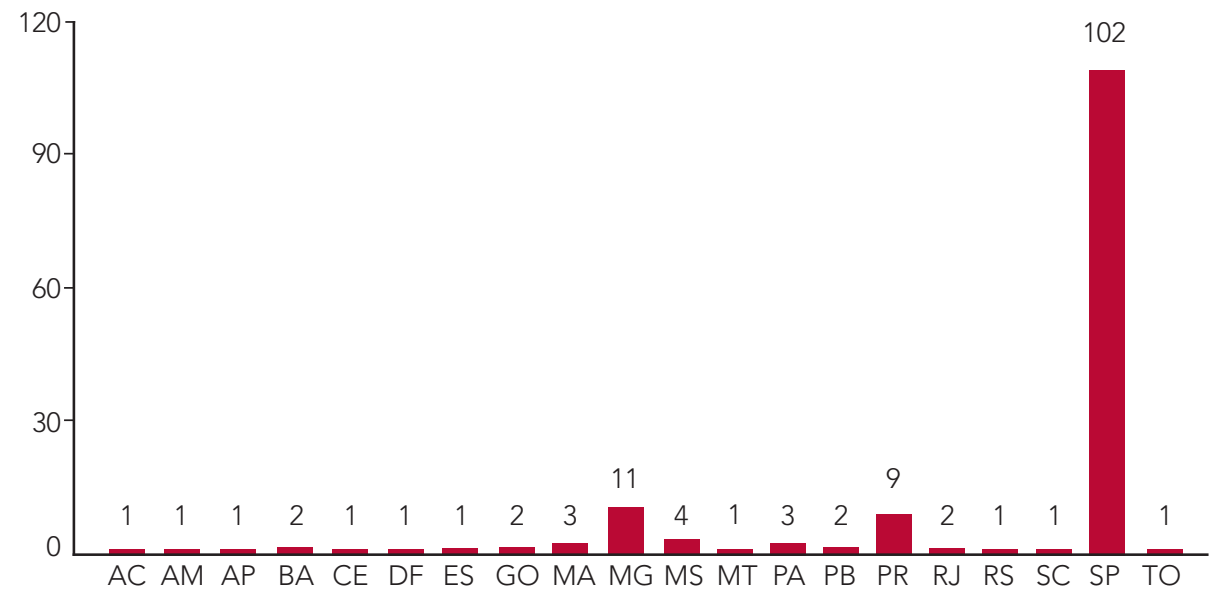

\section{Diversidade de Ações Realizadas}

Como já enfatizado, a pesquisa-participante e/ou a pesquisa-ação são a melhor oportunidade oferecida pelo CEEA para o exercício da educação ambiental. Os projetos idealizados, construídos e trabalhados pelos alunos almejam resgatar problemas sociais e/ou ambientais da sua comunidade de origem. Um anseio os move ao idealizarem seus projetos, que é o de conseguirem estabelecer certo equilíbrio de forças entre a degradação observada em vários ângulos da vivência do homem moderno e a preservação/conservação dos ecossistemas, oferecendo como resultado uma maior segurança e qualidade de vida.

Mas é preciso reconhecer que este binômio homem e natureza não é um tema nada trivial para ser compreendido e trabalhado. Em primeiro lugar, basta uma rápida leitura dos grandes estudiosos da natureza, como Odum [20], Begon [1] e Ricklefs [21] para perceber como é complexo o funcionamento dos ecossistemas, uma vez que os processos que regem seu desenvolvimento ocorrem em diferentes escalas de espaço e tempo, interagindo com uma impressionante diversidade de vida, de metabolismos, de ciclos biológicos e de mobilidades. Em segundo lugar, neste cenário 
ecológico aparentemente instável insere-se o homem, com sua forma de organização e expansão socioeconômica e política, alterando os padrões de estruturação e funcionamento dos ecossistemas, dificultando ainda mais sua compreensão. É este desafio ambiental-social-econômico e político que é apresentado aos alunos para subsidiar a construção de seus projetos. É este o momento em que para eles ocorre uma maior imersão na realidade a ser trabalhada. É esta bagagem exercitada pela pesquisa-participante e/ou pesquisa-ação que os torna melhor capacitados para a multiplicação.

Imbuídos deste ideal e fazendo uso das ferramentas e métodos apropriados, os alunos geram interessantes trabalhos socioambientais. As abordagens temáticas dos projetos concluídos como monografias são bem diversas, como: água (bacia hidrográfica; qualidade de água; poluição e contaminação; nascentes e mananciais); solo (mata ciliar; erosão; uso e ocupação do solo rural e urbano); resíduos e poluição do ar (resíduos sólidos; resíduos líquidos; poluição atmosférica veicular, industrial e de queimadas); meio ambiente e impactos antrópicos (degradação ambiental; fauna e flora nativa; desmatamento; ecologia geral aplicada); saúde pública (saneamento básico; doenças de veiculação hídrica); mitigação de problemas ambientais (educação ambiental formal e informal; percepção; aterro sanitário; reflorestamento; preservação e conservação de ecossistemas; legislação ambiental); meio ambiente e desenvolvimento (sociedade de consumo; exclusão e marginalização social; desenvolvimento econômico e sustentabilidade).

O componente ecológico presente nos projetos é aplicado tanto para uma educação "sobre o meio" quanto para uma educação "para o meio". Lucas [11] cita que, embora necessária, a educação "sobre o meio" não é suficiente para o desenvolvimento de uma educação "para e/ou com o meio", ou seja, incluindo componentes sociais, políticos e econômicos. Um exemplo de uma educação "para o meio" seria um projeto que tivesse como objetivo, além de estudar a poluição de um rio, também a tomada de decisões e ações para diminuir o impacto ambiental observado, agindo tanto em âmbito pessoal - o que eu posso e devo fazer - como no coletivo - encaminhamento de propostas, cobrança e acompanhamento das decisões políticas das instituições responsáveis, entre outras [9, 26].

Algumas propostas de projetos do CEEA já apresentam esta preocupação com a mitigação dos impactos ambientais, ou seja, de educação "para o meio", estabelecendo aspectos de gestão ambiental. O sucesso neste particular parece depender muito das parcerias e apoios firmados pelos alunos para a execução dos seus projetos, ou se o aluno já faz parte de uma organização ou instituição voltada para a gestão ambiental, como por exemplo ONGs, Comitês de Bacia, Secretarias de Meio Ambiente, entre outras, o que favorece o envolvimento da organização e de seus recursos.

Os benefícios das parcerias devem ser enfatizados aqui. É importante reconhecer que, no exercício de planejamento e execução dos projetos, o aluno que envolve parcerias é favorecido profissionalmente. Na parceria pode ocorrer um aprimoramento das metas programadas no projeto em resposta às experiências acumuladas pelo parceiro, potencializando os resultados alcançados. Outro resultado positivo advém do exercício da inter e intradisciplinaridade proporcionada pelo parceiro, com diálogos e comunicações mais enriquecedoras que auxiliam no cumprimento de metas. Por fim, as parcerias 
podem representar uma redução de tempo e de recursos para completar a proposta.

Dentre os muitos projetos concluídos no âmbito do curso, vários parceiros acompanharam todas as etapas de trabalho, enquanto outros participaram de forma pontual, viabilizando o cumprimento de algumas metas. Alguns exemplos de parcerias que auxiliaram ou viabilizaram muitos dos projetos executados incluem universidades federais, estaduais e particulares; centros de pesquisa, delegacias de ensino e escolas no âmbito municipal e estadual, públicas e privadas, escolas indígenas, prefeituras e secretarias de meio ambiente, comitês de bacia, ONGs, associações de bairro e de moradores, polícia militar, polícia ambiental, SEBRAE, estações ecológicas, capitania de navegação fluvial, parques estaduais, paróquias e dioceses, entre muitas outras.

De um modo geral, avaliando-se os objetivos do CEEA, refletidos na natureza dos projetos e dos resultados alcançados pelos alunos, percebe-se que o mesmo segue uma corrente de gestão ambiental, categoria estabelecida por Sorrentino [24] como uma abordagem mais abrangente, que considera a educação ambiental como educação política, relacionando fatores ecológicos, históricos, políticos e sociais [22].

\section{CONSIDERAÇÕES FINAIS}

Na concepção do CEEA, tem-se procurado envolver de forma significativa os setores educacionais e de outras organizações em nível local, regional e nacional. Com o apoio de profissionais de diferentes áreas do conhecimento e de diferentes instituições, as bases e objetivos do curso evoluíram substancialmente desde a sua criação, sempre no compasso das demandas da realidade, integrando múltiplos aspectos na busca de soluções para a crescente crise socioambiental. Podendo ser considerado de relevância para o cenário nacional, o curso, por meio do desenvolvimento de projetos, estimula elementos de difusão e de multiplicação nas diversas regiões do Brasil, consubstanciando a troca e socialização de conhecimentos. Os resultados do curso são reavaliados continuamente no sentido de identificar necessidade de melhoria na sua estrutura e detectar a efetividade dos objetivos idealizados, em especial a formação do ser humano integral.

No que tange a adotar a bacia hidrográfica como unidade de estudo, aprendizado e intervenção, esta unidade político-geográfica permite obter uma visão mais ampla do homem em seu meio ambiente, uma vez que são discutidos os principais usos, impactos e consequências das atividades antrópicas sobre os sistemas terrestre e aquático. Ressalta-se ainda a importância dos trabalhos de campo e de laboratório previstos nesta proposta educativa, pois, concomitantemente às aulas, os professores e demais profissionais participantes têm a oportunidade de desenvolver o olhar holístico e integrado do mundo. Da forma como foi originalmente concebido, o curso evoluiu muito no exercício da prática da educação ambiental, adotando propostas pedagógicas de vanguarda e que se pautam na conscientização política das pessoas, na desigualdade social, na degradação do ambiente, a fim de se modificar as relações de dominação da sociedade. 
Por tudo o que foi exposto neste trabalho percebe-se que o curso aqui apresentado tem buscado ser atual na forma de conduzir os seus objetivos, com enfoque notadamente humanístico, valorizando a essência de cada participante, primando pelo bom relacionamento entre todos os envolvidos e criando uma atmosfera de solidariedade onde todos buscam colaborar com todos.

Os organizadores do curso também se preocupam em estabelecer as bases para uma pedagogia histórico-crítica, cujo objetivo é fazer com que as pessoas compreendam o impacto de fatores sociais e ambientais, buscando o que é denominado por "sustentabilidade". Assim, ao se desenvolver práticas de educação ambiental com ênfase nos aspectos culturais e/ou sociais, obtêm-se uma maior contribuição para a manutenção ou para a transformação das condições sociais existentes.

Por intermédio da metodologia adotada e das reformatações ocorridas, o curso ampliou seu universo de atuação. Inicialmente restrito aos municípios do Estado de São Paulo, o curso extrapolou seus limites territoriais atingindo outros estados do País, como Paraná, Mato Grosso, Mato Grosso do Sul, Amazonas, Maranhão, Pará, Paraíba, Goiás, Minas Gerais, Espírito Santo, Santa Catarina, Tocantins, Amapá e outros. Esta expansão, associada ao potencial multiplicador e de mobilização que é promovido durante a execução dos projetos, torna a proposta mais abrangente. A título de exemplo, o poder de mobilização dos projetos executados no período de 1997 a 2001 foi de mais de 6.000 alunos em diversas regiões do país [19].

Um destaque deve ser feito com respeito à contribuição do curso para a formação continuada dos alunos. Uma análise feita por Moraes et al. [19], no período de 1997 a 2006, mostrou que 39 ex-alunos do curso (26\%) foram absorvidos em programas de pós-graduação em nível de mestrado e doutorado, pertencentes a instituições como: USP (POLI-USP), UNESP, UNIMEP, UFSCar, UNIARA, UNICAMP e UNIFAL.

Outra contribuição do CEEA para a sociedade tem sido as publicações que repassam a experiência educativa exercida no CRHEA. Várias obras apresentam este trabalho de contato com a comunidade e socializam o conhecimento adquirido da prática da interdisciplinaridade. Algumas destas obras são: Educação Ambiental para o Turismo Sustentável - Vivências Integradoras e Outras Estratégias Metodológicas [14]; Educação Ambiental - Implantando Cursos Sustentáveis [19]; Educação Ambiental - Momentos de Reflexão [13]; Educação Ambiental - Transformando Utopia em Realidade [12]; Manual para Avaliação da Qualidade da Água [17]; Manual para Diagnóstico da Qualidade dos Recursos Hídricos [18].

Diante de toda a realidade global não há momento mais propício e, por que não dizer, improrrogável, para se estabelecer rumos mais sustentáveis do que o atual, quer seja no ambiente rural, quer seja nas cidades. As IES, ao reconhecerem esta urgência, esforçam-se por estar plenamente atuantes, realizando seu papel neste processo e corroborando o trabalho de muitas organizações no mundo inteiro que despertam para o papel de trabalhar pela melhoria ampla das sociedades, seguindo os passos da Agenda 21 Global e Brasileira.

As IES reconhecem que resultados concretos ocorrem na capilaridade, em nível de governos locais e comunidades. No Brasil, a Política de Sustentabilidade das IES potencializa muitos trabalhos neste nível, como, por exemplo, os trabalhos da ICLEI 
- Local Governments for Sustainability (Governos Locais para a Sustentabilidade), uma organização global preocupada com o desenvolvimento sustentável na vida do ambiente urbano, sendo este um forte componente do território brasileiro que, se não corrigida a sua gestão, manterá a caminhada, a passos largos, para um quadro de inviabilidade da qualidade de vida e ambiental.

O ICLEI, como uma associação internacional de governos locais e outras organizações governamentais, conta com uma agenda de ações que tem como fator de sucesso a necessidade de investir em conscientização e capacitação dos atores - governos locais e comunidades - para as questões ambientais, em detrimento de uma visão puramente econômica. Estados (AM, SP, MG) e muitos municípios brasileiros (como São Paulo, Belo Horizonte, Manaus, Rio de Janeiro, Porto Alegre, Curitiba, Goiânia, entre outros) estão associados ao ICLEI, que apresenta oito agendas de ações estratégicas para melhoria do ambiente urbano mundial a serem adotadas a partir de 2012, quais sejam: economia local viável baseada em ciclos de materiais de berço ao berço; política de sustentabilidade urbana integrada; cidades ecoeficientes; BiodiverCidades; cidades baixo-carbono e carbono-neutras; cidades de baixo risco (resilientes); infra-estrutura verde e comunidades felizes e saudáveis.

De tudo o que foi apresentado, a Escola de Engenharia de São Carlos, por meio das atividades do Curso de Especialização em Educação Ambiental do Centro de Recursos Hídricos e Ecologia Aplicada, tem trabalhado para a valorização e a viabilização de esforços de seu quadro de recursos humanos e de parceiros para um redirecionamento dos rumos atualmente adotados pela sociedade. Como pensamento impresso dos profissionais envolvidos no CEEA, temos que "O Universo no qual estamos imersos é complexo e imenso. Não sabemos se nossas ações têm alguma importância no desenrolar eterno de todo o cosmos. O que podemos observar em termos de causas e efeitos é ínfimo, considerando as limitações de nossos corpos e de nossa ciência. Mas o que queremos evitar é que nossas ações sejam deletérias a nós, aos outros seres que são dependentes de nossas decisões e ao futuro desse conjunto que é a Terra. Achamos que há uma razão para estarmos aqui e não queremos que nossos próprios atos nos impeçam de conhecê-la. Isso talvez seja um dos motivos que nos leve a divulgar a Educação Ambiental”.

\section{REFERÊNCIAS}

[1] BEGON, M.; TOWNSEND, C.R.; HARPER, J.L. Ecologia: de indivíduos a ecossistemas. $4^{\mathrm{a}}$ ed. Porto Alegre: Artmed, 2007. 752p.

[2] BORDENAVE, J. ; PEREIRA, A. Estratégias de ensino aprendizagem. $4^{\text {a }}$. ed. Petrópolis: Vozes, 1982.

[3] BRIGANTE, J.; ELER, M.N.; MORAES, A.J. de. Avaliação Rápida de Pequenos Cursos de Água e Interpretação Ambiental: trabalho de campo nas bacias hidrográficas do ribeirão do Lobo e rio Itaqueri, Brotas/Itirapina/SP. In: MATHEUS, C.E. e MORAES, A.J. de (orgs.). Educação ambiental - momentos de reflexão. São Carlos: RiMa Editora, pg. 185-189, 2012. 
[4] CAMPOS, E.G.C. Alguns aspectos da teoria de Piaget. Trabalho Temático do Projeto ECOCIPLAN. CAPES/PADCT. São Carlos: EESC-USP, 1992. 1op.

[5] CASTRO, R.S: SPAZZIANI, M.L: SANTOS, E.P. Universidade, Meio Ambiente e Parâmetros Curriculares Nacionais. In: LOUREIRO, C.F.; LAYARGUES, P.P.; CASTRO, R.S. (org.) Sociedade meio ambiente: a educação ambiental em debate. 2 ed. São Paulo: Cortez, p.157-179, 2002.

[6] DEPRESBITERES, L. Avaliação da Aprendizagem na Educação Ambiental uma relação muito delicada. In: SANTOS, J.E.; SATO, M. A contribuição da educação ambiental à esperança de pandora. São Carlos: RiMa Editora, p. 531-557, 2001.

[7] FREIRE, P. Pedagogia do Oprimido. Rio de Janeiro: Paz e Terra, 1979.

[8] GAJARDO, M. Pesquisa Participante na América Latina. São Paulo: Brasiliense, 1986.

[9] GIORDAN, A.; SOURCHON, C. La educación ambiental: guia práctica. Sevilla: Drada Editora S. L., 1997.

[10] GUIMARÃES, S.T. de L. Transformando utopia em realidade: sobre educar para a esperança... In: MATHEUS, C.E. e MORAES, A.J.de (orgs.). Educação ambiental - momentos de reflexão. São Carlos, RiMa Editora, p. 23-34, 2012.

[11] LUCAS, A.M. Educación ambiental para una era nuclear. Hadase 8, p.123-136, 1992.

[12] MATHEUS et al. Educação Ambiental - transformando utopia em realidade. RiMA Editora, 2012.

[13] MATHEUS, C.A. Educação e transformação da pessoa humana - reflexões sobre a vida, tendo como "pano de fundo" o curso de especialização em educação ambiental e recursos hídricos da Universidade de São Paulo. In: MATHEUS, C.E. e MORAES, A.J.de (orgs.). Educação ambiental - momentos de reflexão. São Carlos: RiMa Editora, p. 254-269, 2012.

[14] MATHEUS, C.A.; MORAES, A.J. de.; CAFFAGNI, C.W.A. Educação ambiental para o turismo sustentável - vivências integradoras e outras estratégias metodológicas. São Carlos: RiMa Editora, 2005. 162p.

[15] MMA (Ministério do Meio Ambiente). Panorama da biodiversidade global 3. Eliana Jorge Leite (tradutora). Brasília: Ministério do Meio Ambiente, Secretaria de Biodiversidade e Florestas. 2010. 94p.

[16] MORAES, A.J. de. A relevância regional e nacional do curso de especialização em educação ambiental do Centro de Recursos Hídricos e Ecologia Aplicada (CRHEA-EESC-USP): uma abordagem avaliativa. 2004. 174p. Dissertação (Mestre em Desenvolvimento Regional e Meio Ambiente). Araraquara: Centro Universitário de Araraquara, 2004.

[17] MORAES, A.J. de. Manual para avaliação da qualidade da água. São Carlos: RiMa Editora, 2001. 45p.

[18] MORAES, A.J. de; BRIGANTE, J. Manual para diagnóstico da qualidade dos recursos hídricos. São Carlos: EESC-USP, 2010. 74p.

[19] MORAES, A.J. de; SCHULZ, H.E.; MATHEUS, C.E. Educação ambiental - implantando cursos sustentáveis. São Carlos: EESC-USP, 2006. 134p.

[20] ODUM, E.P. Ecologia. Rio de Janeiro: Editora Guanabara Koogan S.A., 1988. 434p. 
[21] RICKLEFS, R.E. A economia da natureza. $6^{a}$ ed. Rio de Janeiro: Editora Guanabara Koogan S.A., 2011. 546p.

[22] ROSELAN, M. Toward sustainable communities - solutions for citizens and their goverments. Canadá: New Society Publishers, $4^{\mathrm{a}}$ Edition. 2012. 363p.

[23] SILVEIRA, A. Abordagens pedagógicas em educação ambiental. In: MATHEUS, C.E. e MORAES, A.J. de (orgs.). Educação ambiental - momentos de reflexão. São Carlos: RiMa Editora, p. 100-112, 2012.

[24] SORRENTINO, M. Educação ambiental e universidade: um estudo de caso. Tese de doutoramento. São Paulo: Faculdade de Educação/USP, 1995.

[25] TAMAIO, I. O Professor na construção do conceito de natureza: uma experiência de educação ambiental. São Paulo: ANNABLUME/WWF, 2002.

[26] TEROSSI, M.J.; SANTANA, L.C. Educação ambiental no Brasil: fontes epistemológicas e tendências pedagógicas. Rev. Eletrônica Mestr. Educ. Ambient. ISSN 1517-1256, v. 24, jan-jul. de 2010. Disponível em: http://seer.furg.br/remea/article/viewFile/3906/2333>. Acesso em 16 set. 2014.

[27] THIOLLENT, M. Metodologia da pesquisa ação. São Paulo: Ed. Cortez, 1985.

[28] TUNDISI, J. G. A bacia hidrográfica como unidade de pesquisa, gerenciamento e planejamento. Trabalho Temático do Projeto ECOCIPLAN CAPES/ PADCT. São Paulo: USP, 1992. 12p.

[29] TUNDISI, J.G. (ed.) Limnologia e manejo de represas. Vol. I, Tomos 1 e 2. São Carlos: EESC-USP/ACIESP, (Série Monografias em Limnologia), 1988.

[30] TUNDISI, J.G. et al. A utilização do conceito de bacia hidrográfica como unidade para atualização de professores de ciências e geografia: o modelo Lobo (Broa), Brotas/ Itirapina. In: TUNDISI, J. G. (ed.) Limnologia e Manejo de Represas. Vol. I, Tomo 2. São Carlos: EESC-USP/ACIESP (Série Monografias em Limnologia), 1988.

[31] TUNDISI, J.G. et al. Environmental education project: case study of Brazil. In: ILEC. Report of Promotion Environmental Education in Developing Countries. Kusatsu: ILEC, p. 43-70, 1992.

[32] TUNDISI, J.G. et al. Environmental education project in brazil: the watershed and the water quality approach. In: ILEC. Report of Promotion Environmental Education in Developing Countries. Kusatsu: ILEC, p.19-20, 1993.

[33] TUNDISI, J.G. Formação de Professores em Ciências Ambientais. In: USP/ CECAE (org.) A universidade e o aprendizado escolar de ciências. Projeto USP/BID - formação de professores de ciências (1990-1993). São Paulo: USP, p. 115-117. 1993.

[34] TUNDISI, J.G. Local Community Involvement in Environmental Planning and Management Focus on River Basin Management, the Lobo, Broa Reservoir Case Study. Expert Group on Environmental and Management for Local and Regional Development: Focus on Training Aspects Derived from Studies of Inland Water Management. Otsu and Nagoya: UNCRD/ILEC/UNEP, 1986. 29p.

[35] TUNDISI,J.G.; CAMPOS, E.G.C.; MATHEUS, C.E.; MORAES, A.J. de. Promotion of environmental education in developing countries: case study of Brazil. In: Report of ILEC (International Lake Environment Committee), p. 17-20, 1994. 
[36] TUNDISI, J.G.; SCHIEL, D. Sistema de atualização de professores de ciências e geografia com a utilização do conceito de bacia hidrográfica como unidade de ensino: conceitos básicos, projeto e perspectivas. São Carlos: IFQSC/ USP-CRHEA/EESC-CAPES-PADCT, (Publicação Especial n.1), 1986. 13p.

[37] UNESCO. Educação para um Futuro Sustentável - Uma visão transdisciplinar para uma ação compartilhada. Brasília: Ed. IBAMA, 1999. 118p.

CARLOS EDUARDO MATHEUS doutor em Engenharia Hidráulica e Saneamento pela Escola de Engenharia de São Carlos (EESC-USP) - e-mail: matedu@uol.com.br

AMERICA JACINTHA De moraes mestre em Desenvolvimento Regional e Meio Ambiente pelo Centro Universitário de Araraquara (UNIARA). Especialista em laboratório de limnologia e de educação ambiental

JANETE BRIGANTE doutora em Ecologia e Recursos Naturais pela Universidade Federal de São Carlos (UFSCar) 